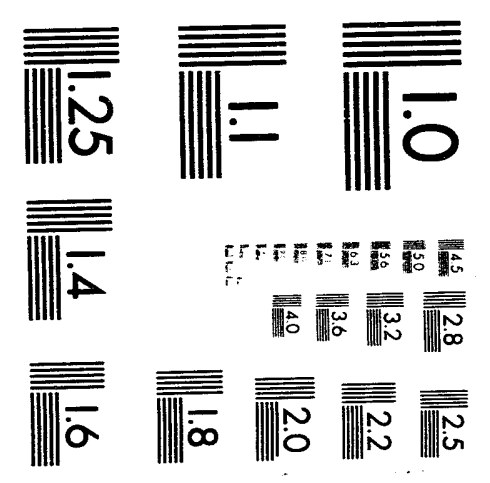



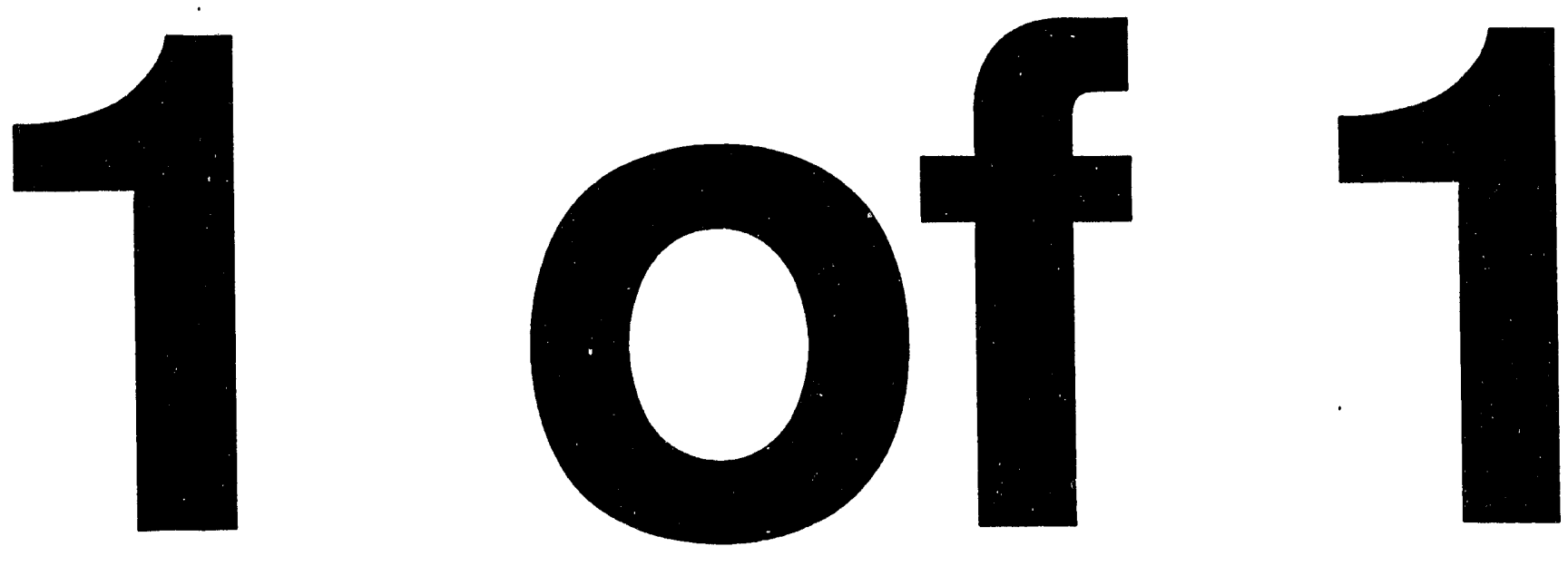


\title{
HIGH CONVERSION OF COAL TO TRANSPORTATION FUELS FOR THE FOTURE WITH LOW HC GAS PRODUCTION
}

Frogress Report No. 4

(Covering the Period July 1 - September 30, 1993)

Wendell $\mathrm{H}$. Wiser, Principal Investigator Alex G. Oblad, Co-Principal Investigator

\author{
Department of Chemical and Fuels Engineering \\ University of Utah \\ salt Lake city, Utah 84112
}

Prepared for the United States Department of Energy under Contract No. DE-AC22-92PC92121

October, 1993 


\title{
HIGH CONVERSION OF COAL TO TRANSPORTATION FUELS FOR THE FUTURE WITH LON HC GAS PRODUCTION
}

Progress Report No. 4

(Covering the Period July 1 - September 30, 1993)

\begin{abstract}
Wendell H. Wiser, Principal Investigator Alex G. Oblad, Co-Principal Investigator
\end{abstract}
Department of Chemical and Fuels Engineering University of Utah
Salt Lake City, Utah 84112

\footnotetext{
Prepared for the United States Department of Energy under Contract NO. DE-AC22-92PC92121
} 
DISCLAIMER

This report was prepared as an account of work sponsored by an agency of the United States Government. Neither the United States Government nor any agency thereof, nor any of their employees, makes any warranty, express or implied, or assumes any legal liability or responsibility for the accuracy, completeness, or usefulness of any information, apparatus, product, or process disclosed, or represents that its use would not infringe privately owned rights. Reference herein to any specific commercial product, process, or service by trade name, trademark, manufacturer, or otherwise does not necessarily constitute or imply its endorsement, recommendation, or favoring by the United States Government or any agency thereof. The views and opinions of authors expressed herein do not necessarily state or reflect those of the United States Government or any agency thereof. 


\section{PERSONNEL}

In addition to the Principal Investigators, research personnel participating in this project during the reporting period are:

\section{Belma Demirel, Graduate student \\ Qiuping Yang, Graduate student}

\section{OBJECTIVES AND SCOPE OF THE RESEARCH PROJECT}

An announced objective of the Department of Energy in funding this work, and other current research in coal liquefaction, is to produce a synthetic crude from coal at a cost lower than $\$ 30.00$ per barrel (Task A). A second objective, reflecting a recent change in direction in the synthetic fuels effort of DOE, is to produce a fuel which is low in aromatics, yet of sufficiently high octane number for use in the gasolineburning transportation vehicles of today. To meet this second objective, research was proposed, and funding awarded, for conversion of the highly-aromatic liquid product from coal conversion to a product high in isoparaffins, which compounds in the gasoline range exhibit a high octane number (Task B).

Experimental coal liquefaction studies conducted in a batch microreactor in our laboratory have demonstrated potential for high conversions of coal to liquids with low yields of hydrocarbon (HC) gases, hence small consumption of hydrogen in the primary liquefaction step. Ratios of liquids/HC gases as high as $30 / 1$, at liquid yields as high as $82 \%$ of the coal by weight, have been achieved. The principal objective of this work is to examine how nearly we may approach these results in a 
continuous-flow system, at a size sufficient to evaluate the process concept for production of transportation fuels from coal.

A continuous-flow reactor system ( $1 / 2$ inch inside diameter) is to be designed, constructed and operated. The system is to be computer-operated for process control and data logging, and is to be fully instrumented. The primary liquid products will be characterized by GC, FTIR, and GC/MS, to determine the types and quantities of the principal components produced under conditions of high liquids production with high ratios of liquids/HC gases. From these analyses, together with GC analyses of the HC gases, hydrogen consumption for the conversion to primary liquids will be calculated. Conversion of the aromatics of this liquid product to isoparaffins will be investigated, to examine the potential for producing a transportation fuel form coal with satisfactory octane rating but low in aromatic content. 


\section{ACTIVITY FOR THE REPORTING PERIOD}

\section{TASK A}

As explained in the previous Report (No. 3), the size of the reactor designed for the present work, together with the very rapid throughput of reactants, including hydrogen at 1500 psig, led to the imposition of more stringent safety conditions for location of the present system than were contemplated when the proposal was written. For example, the safety services department of the University required that all of the electrical connections should be explosion proof, together with other aspects of the system insofar as was possible. These reevaluations created a need for locating the system in a different building, leading to modifications to the building not previously anticipated.

During the time period of the present report, the work of preparation of the space has been completed by the University shops personnel to meet all of the features specified from safety considerations, as well as those necessary for operation of the system, including the very large electrical power demand. The basic reactor vessel has been located inside of the barricade, and work has commenced to complete the assembling of the total reactor system.

It should be noted that the need to operate the system in a completely safe manner was firmly emplanted in our minds from the time of writing of the proposal for the research. The evolution in thinking concerning what may be deemed necessary for that safe operation, as viewed today compared with the time of installation 
of a prior, smaller-scale reactor system 15 years ago, was not anticipated. However the increased precautions to ensure safe operation are not criticized, as they may prevent an accident, or minimize injury in the event of an accident.

In the work performed under the previous contract, utilizing a batch microreactor, it was demonstrated that as much as $82 \%$ by weight of a Wyodak subbituminous coal could be converted to liquids in times as short as three seconds. Ratios of liquids to hydrocarbon (HC) gases at these short times were of the order of $30 / 1$, on a weight basis. Analyses of the data led to the conclusion that the HC gases formed at these short times originated from the short aliphatic side chains on the coal structure, mostly methyl groups.

It was concluded that whereas most of the connecting bridges between structural units in the coal were ruptured in the short times of three seconds, rupture of the hydroaromatic portions of the structures did not become significant until times of 10 seconds or longer. These observations led us to wonder whether pressures as high as 1500 psig were really necessary to complete the chemistry surrounding the rupture of the connecting bridges and the stabilization of the free radicals thus formed. We conducted experiments in the microreactor, with all conditions the same as the previous experiments, including reaction temperature of $500{ }^{\circ} \mathrm{C}$ and reaction time of 5 seconds, but at lower pressures. The results are summarized in Table I. 


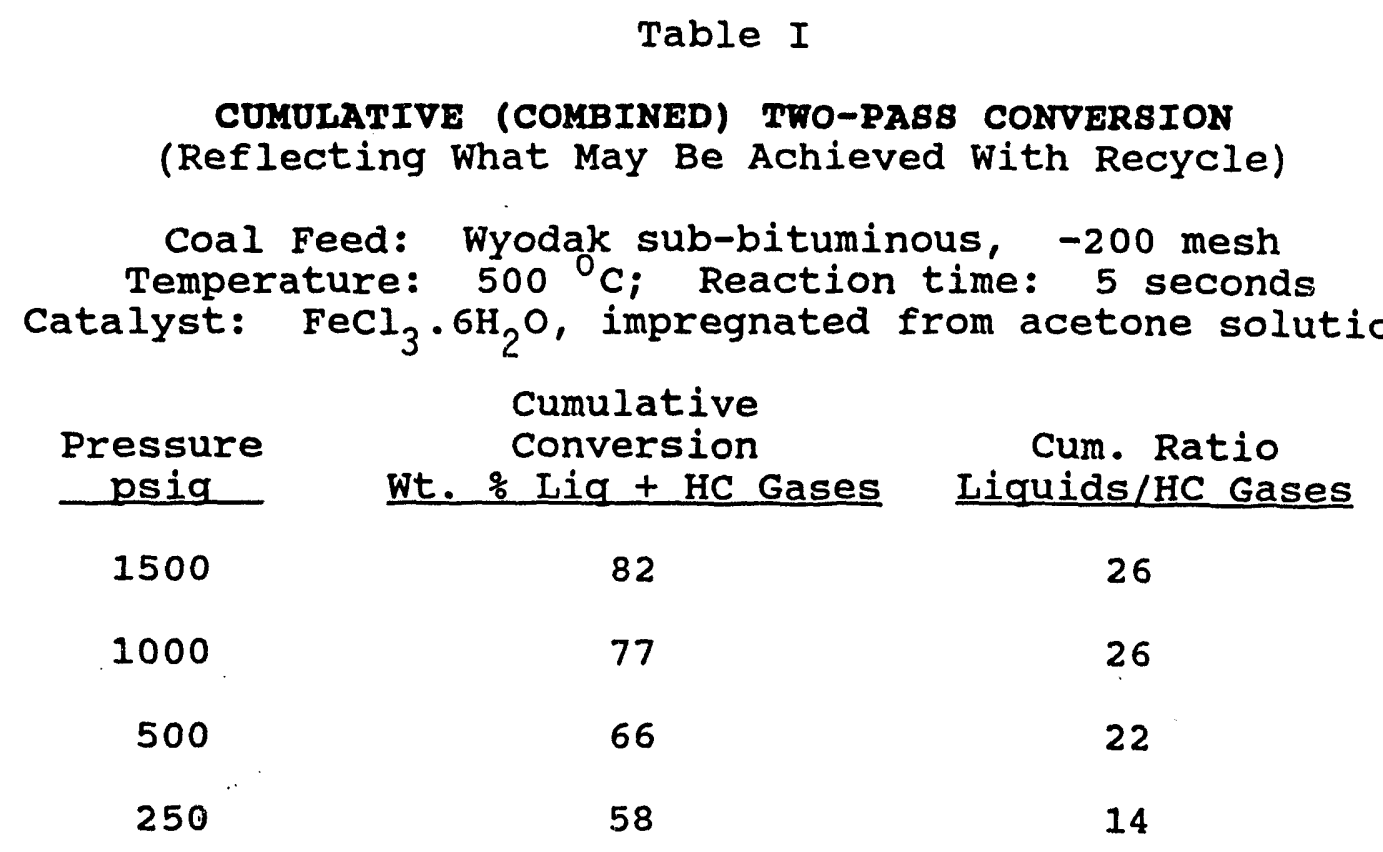

At a hydrogen pressure of 1000 psig, the conversion was reduced only slightly, from $82 \%$ at 1500 psig to $77 \%$ at 1000 psig. The ratio of liquids/HC gases remained high at $26 / 1$. The pressure was then reduced to $500 \mathrm{psig}$. It is noted that the conversion was reduced to $66 \%$ by weight, which value is still high enough for a viable coal liquefaction process. The ratio of liquids/HC gases was reduced only slightly, to $22 / 1$. This value is still far greater than is observed in any other coal liquefaction scheme reported in the literature. We then reduced the pressure to $250 \mathrm{psig}$. The conversion was reduced to $58 \%$ by weight, but with the ratio of liquids/HC gases still high at a value of $14 / 1$

These greatly reduced pressures are of particular interest. It will be remembered that the high conversions to liquids accompanied by very low yields of HC gases depends upon the ability to heat the coal particles to reaction temperature of 
about $500{ }^{\circ} \mathrm{C}$ in very short times of the order of about one second. In turn, this very rapid heating rate is most readily achieved when the coal particles are not surrounded by a Iiquid phase (e.g.fed dry to the reactor). It will be remembered that the Lurgi gasifier, probably the most popular coal gasifier, at least in the U.S., feeds coal dry to the pressurized gasifier using the lock hopper. Lock hopper feeding is a well developed and reliable technology at pressures of the order of 350 psia (the usual operating pressure for the Lurgi gasifier). In addition, it has been reported by manufacturers of the Lurgi gasifier that the Lurgi gasifier, with lock-hopper feed, can operate at pressures of $500 \mathrm{psia}$. The observations reported in Table I thus indicate that the lock-hopper feed system may be used in the advancement of the present technology, probably in a completely reliable manner, and any uncertainty concerning a viable feed system to achieve the results reported is minimized, or even eliminated.

\section{TASK B}

The work of this task focusses on the conversion of aromatic compounds to isoparaffins. The work is motivated by the desire to reduce or even eliminate the use of aromatic compounds to improve the octane rating of unleaded gasoline, and the knowledge that isoparaffins perform the task of octane improvement very well. The study was initiated with methylnaphthalene as feed, and as a potential representative of the types of compounds likely to be present in the liquids to be produced in Task $A$. 
Several catalysts have been used in the work to date, selected from among catalysts available in the market place. Data from those experiments were presented in the prior report. As expected, the catalysts together with the reactor conditions led to high yields of tetralins, as the first step in the series of hydrogenation and cracking reactions which may lead to yields of isoparaffins. Of interest also are the significant yields of decalins. However in the reaction times of 50 minutes, as used for the experiments reported, there wer a no isoparaffins in the product. Cracking had commenced to a significant extent, leading to selected benzene and hexane derivatives. But in general the cracking occurred in the wrong manner, or in the wrong place, for direct production of isoparaffins.

Examination of the data leads to certain conclusions concerning the direction we would like to pursue in the investigation. In the dual functional catalyst used, the hydrogenation function appears to be adequate, although it may be desirable to seek improvement in that function. However the cracking function is obviously inadequate. It may be possible to find a candidate among available catalysts, or to synthesize a new catalyst, which will provide the degree of cracking needed. It appears that selectivity toward cracking at the optimum time, or in the proper location, will likely require synthesis of a new catalyst not now found on the market. One may conclude that it would be desirable to perform the full operation from aromatics to isoparaffins in a single stage, if possible. 
The second observation from the data is that it may be desirable or necessary to utilize separate stages for the hydrogenation and the cracking steps, permitting different temperatures, pressures and catalysts in each stage, in order to obtain an adequate amount of isoparaffins per pass which may indicate the possibility of a viable process.

An extensive listing of available catalysts, appearing in the oil and Gas Journal, was examined and seven catalysts were selected on the basis of their composition and/or announced functions. Requests to the respective companies which manufacture or market the catalysts selected have been initiated. It is considered desirable to first test catalysts available in the market, before embarking extensively into a program of systhesis of new catalysts.

Work will continue on assembling the reactor system for the continuous conversion of coal to liquids, followed by shake-down tests to yield smooth and reproducible operation of the system. As catalysts are received from the manufacturers, they will be tested in relation to production of isoparaffins from aromatics. 

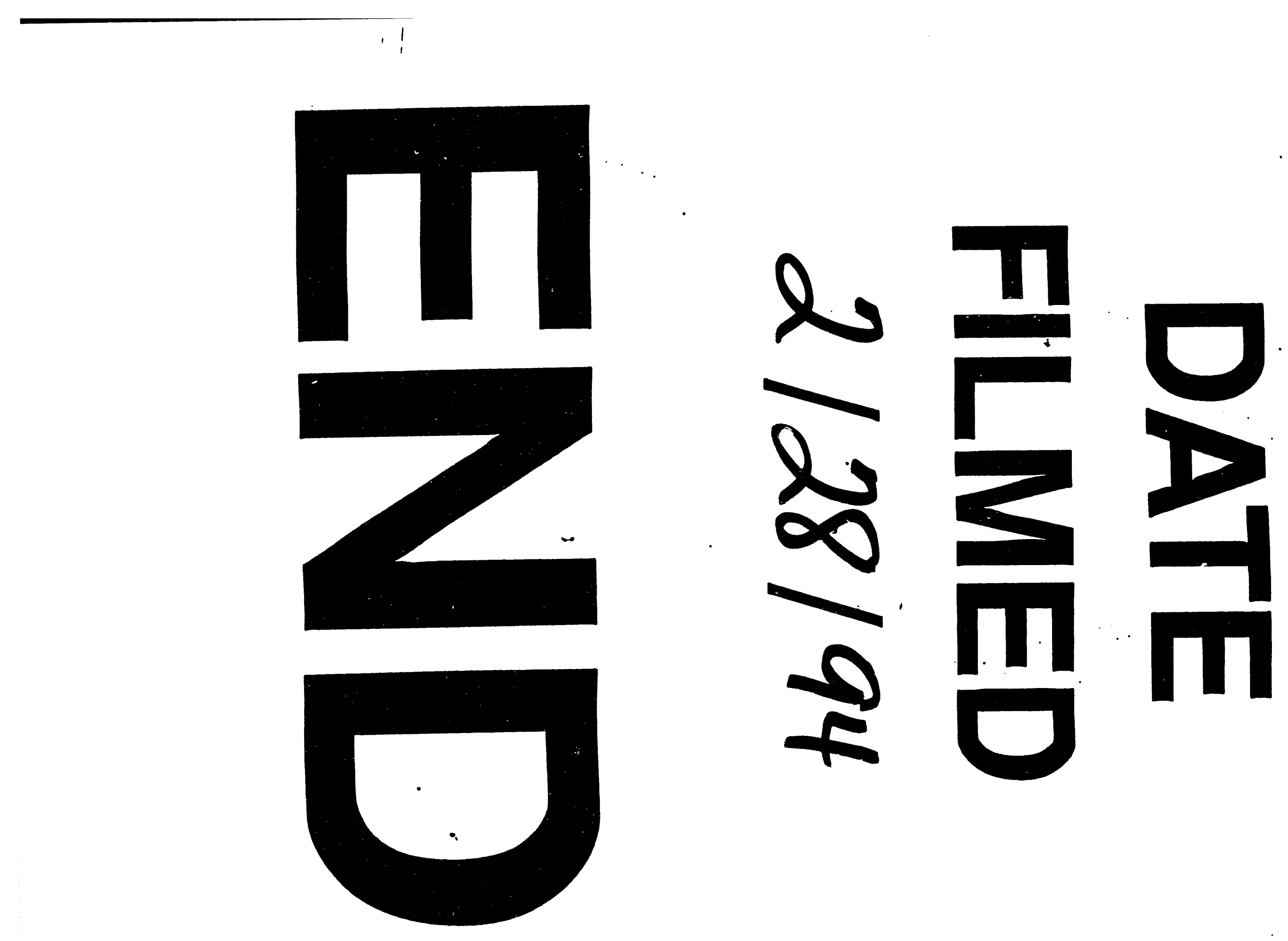
